\title{
EFFECT OF ACTIVE SMOKING AND SECOND-HAND SMOKE ON ASTHMA OF YOUNG PEOPLE: COMMUNITY HEALTH SURVEY
}

Kil Yong Choi ${ }^{1}$, Kwang Sung Park ${ }^{2}$ and Ho Hyun Kim ${ }^{3}$

Abstract- Background: Korean society has become globalized and Westernized, smoking and drinking among adolescents has created a huge social problem, representing an increased risk in relation to human development. Methods: This research is aimed at measuring the effects of active and passive smoking on asthma among Korean adolescents using data (Community Health Survey) from the 2013 Korea Youth. Data are analyzed from 24,794 respondents in their 20s. Respondents with asthma were identified from the results of logistic regression analysis (SAS 9.3., SAS Inc., Cary, NC, USA) to examine the effects of smoking in relation to this condition in the present study. Results: The chi-square test, showed that the significance probability by sex $(p=0.1598)$ was not significant. However, age $(p=0.0372)$ and level of education $(p<0.0001)$ were significant. In the current smoking category, responses of "no smoking", "everyday", and "sometimes" were given by 330 (74.3\%), 99 $(22.3 \%)$, and $15(3.4 \%)$ of respondents, respectively, representing a statistically significant difference $(p=0.0012)$. In terms of the amount of smoking, considering the prevalence of lifelong smokers $(n=114,25.7 \%)$ and non-smokers $(n=330,74.3 \%)$ diagnosed with asthma, non-smokers were greatly affected by second-hand smoke. Conclusions: In conclusion, it is thought that the government should change the perception of smoking and exposure to children and adolescents.

Keywords - asthma, lifetime smoking, current smoking, household secondhand smoke

\section{INTRODUCTION}

Adolescents are exposed to smoking and drinking at an early stage of life, and this phenomenon exhibits an increasing trend [1-4]. On a worldwide basis, smoking status was estimated to account for up to 5.4 million deaths in $2005,6.4$ million in 2015, and 8.3 million deaths in 2030. In the 2015 estimate, cancer represented the highest number of smoking-related deaths, at 2.1 million, and in particular, the number of deaths caused by respiratory system cancer, including lung cancer, was near 1.2 million [5]. The smoking rate in Korean males and females aged 20 and over was $79.3 \%$ in 1980, dropping to $52.3 \%$ in 2005; however, the smoking rate in adults aged 20 - 40 has remained above 60.0\%, because the smoking rate among females was $5.8 \%$ in 2005, having increased continually since 1980 [6, 7]. Smoking can be a detrimental factor in the development of respiratory disease, chronic obstructive pulmonary disease, ischemic heart diseases, and cerebrovascular disease. In fact, about 1.9 million people die annually from these diseases. Recently, the effects of secondhand smoking on children and adolescents with asthma has attracted a great deal of research attention [8-12]. Asthma is more frequent in children and adolescents than adults, and it can be dangerous when asthma occurs in a susceptible group of people. The prevalence of asthma in youth in Korea is about 9\%, and its rate has shown a tendency to increase every year [13-15]. Asthma is a significant factors that not only diminishes adolescents' academic performance but also affects the activities in their school life; thus, this disease needs to be cured as soon as possible to prevent youth from having social problems [16].

\section{MATERIALS AND METHODS}

A. Subjects-

We selected subjects older than 19 years of age residing in Korea in July 2013 using the sample selection. Adolescent who were highly exposed to smoking were selected from Community Health Survey 2013 to examine the relationship between smoking and a chronic disease, namely asthma. A subset of adults older than 19 years and less than 30 years of age $(\mathrm{n}=$ 24,794) was used to analyze the relationship between active (lifetime smoking, initial smoking age, current smoking, daily smoking, etc.) and passive smoking (second-hand smoke exposure time at home, second-hand smoke exposure time in the workplace, etc.).

\footnotetext{
${ }^{l}$ Environmental Health Center, Korea University Anam Hospital, Department of Environmental Engineering, Pusan National University, Busan, Korea.

${ }^{2}$ Research Institute, Seoul Medical Center, Seoul, Korea.

${ }^{3}$ Dept. of information, Communication and Technology Convergence. ICT Environment Convergence, PyeongTaek University, PyeongTaek, Korea
} 


\section{B. Statistical analysis-}

Data analyses were conducted using commercially available statistical software, SAS 9.2 (SAS Inc., Cary, NC, USA). The demographic variables were sex, age, educational background, region, and marriage, using baseline data collected in the 2013 Community Health Survey. Percentage and cross-correlation analysis were employed to test differences in socio-demographic characteristics between the asthma group and the non-asthma group, as well as asthma status between the smoking and the second-hand smoking group. To determine statistical significance, two-tailed Pearson chi-square statistical tests were performed. Logistic regression analysis was used to examine the data and to show the adjusted odds ratio (aOR) and 95\% confidence interval $(95 \% \mathrm{CI})$.

\section{RESULTS}

A. General characteristics-

In this study population ( $\mathrm{N}=24,794)$, there were 11,434(46.12\%) men and 13,360 (53.88\%) women with asthma disease. The chi-square test, showed that the significance probability by sex $(\mathrm{p}=0.1598)$ was not significant. However, age $(\mathrm{p}=0.0372)$ and level of education $(\mathrm{p}<0.0001)$ were significant. Specifically, in terms of age, there were high distributions of 20 year-old (12.6\%) and 22 year-old subjects (14.0\%). Finally, there appeared to be significant differences in the presence of asthma related to marital status $(\mathrm{p}=0.0025)$ (Table 1$)$.

Table 1. General demographic characteristics

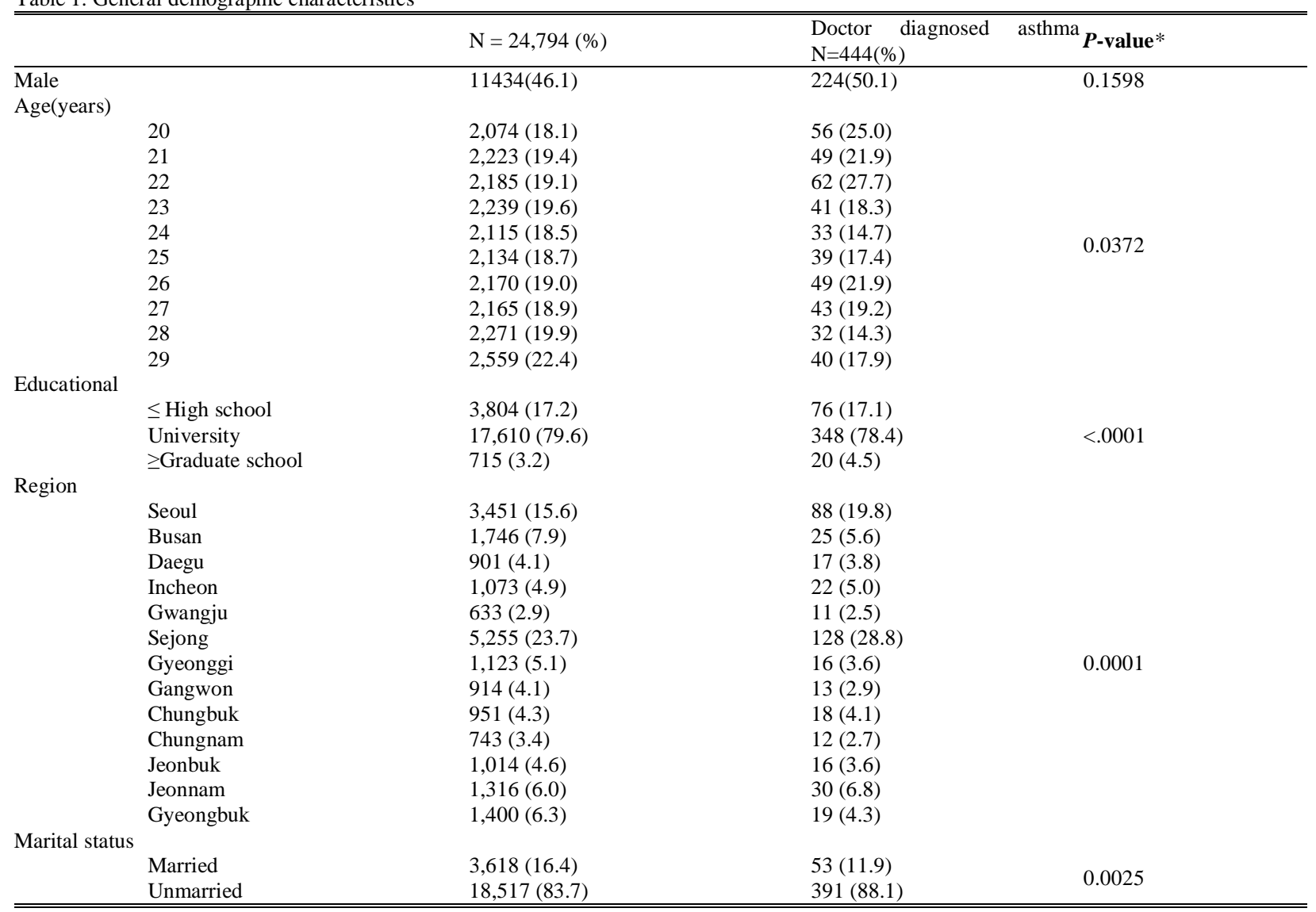

*Individual characteristic; EA, economic activity; OR, odds ratio; CI, confidence interval; NA, no answer

B. Asthma occurs due to direct smoking -

Smoking was found to have a direct effect on the development of asthma (Table 2). It was evident that $34.2 \%$ ( $\mathrm{n}=152$ ) of the subjects had been diagnosed with asthma. There were 152 (34.2\%) smokers that had been diagnosed with asthma, and this result was statistically significant $(\mathrm{p}=0.0025)$. In the current smoking category, responses of "no smoking", "everyday", and "sometimes" were given by 330 (74.3\%), 99 (22.3\%), and 15 (3.4\%) of respondents, respectively, representing a statistically significant difference $(\mathrm{p}=0.0012)$. Finally, for past smoking duration, " $2 \sim 5$ years", " 1 year or less", and "more than 5 years," were reported by $14(3.2 \%), 13(2.9 \%)$, and 7 (1.6\%) respondents, respectively, and this result was statistically significant $(\mathrm{p}=0.0039)$ (Table 2$)$. 
C. Asthma occurs due to passive smoking status-

In terms of the amount of smoking, considering the prevalence of lifelong smokers $(\mathrm{n}=114,25.7 \%)$ and non-smokers(n=330, $74.3 \%$ ) diagnosed with asthma, non-smokers were greatly affected by second-hand smoke. Eleven people had been exposed to smoking more than 3 years, while only 1 person each had experienced smoke exposure of " 4 - 6 years", and "more than six years." This result was statistically significant $(\mathrm{p}=0.022)$. Another $444(100 \%)$ respondents were exposed to second-hand smoke in the workplace, while $414(93.2 \%)$ had been exposed in public spaces (Table 2).

Table 2. Relationship between smoking and asthma

\begin{tabular}{|c|c|c|c|}
\hline & $\mathrm{N}=24,794(\%)$ & $\begin{array}{l}\text { Doctor diagnosed, } \\
\mathrm{N}=444(\%)\end{array}$ & ${ }^{\text {asthma }}{ }_{p \text {-value }}{ }^{*}$ \\
\hline Lifetime smoking (+) & $5,982(27.0)$ & $152(34.2)$ & 0.0025 \\
\hline \multicolumn{4}{|l|}{ Age when smoking started } \\
\hline$<15$ years old & 805 (3.6) & $21(4.7)$ & \multirow{4}{*}{0.7961} \\
\hline $16-20$ years old & $4,353(19.7)$ & $102(23.0)$ & \\
\hline $21-25$ years old & $793(3.6)$ & $27(6.1)$ & \\
\hline$>26$ years old & $25(0.1)$ & $1(0.2)$ & \\
\hline \multicolumn{4}{|l|}{ Current smoking } \\
\hline Every day & 4,327 (19.6) & $99(22.3)$ & \multirow{3}{*}{0.0012} \\
\hline Sometimes & $435(2.0)$ & $15(3.4)$ & \\
\hline Do not smoke. & $17,373(78.5)$ & $330(74.3)$ & \\
\hline \multicolumn{4}{|l|}{ Past smoking period } \\
\hline$<1$ year & $303(1.4)$ & $13(2.9)$ & \multirow{3}{*}{0.0039} \\
\hline $2-5$ years & $593(2.7)$ & $14(3.2)$ & \\
\hline$>5$ years & $319(1.5)$ & $7(1.6)$ & \\
\hline Second-hand smoke exposure at $(+)$ & $2,841(12.8)$ & $362(81.5)$ & 0.1057 \\
\hline \multicolumn{4}{|c|}{ Length of second-hand smoke exposure at home } \\
\hline$<3$ hours & $22,047(99.6)$ & $11(2.5)$ & \multirow[t]{3}{*}{0.022} \\
\hline $4 \sim 6$ hours & $65(0.3)$ & $1(0.2)$ & \\
\hline$>6$ hours & $23(0.1)$ & $1(0.2)$ & \\
\hline \multicolumn{4}{|c|}{ Secondhand smoke exposure in the workplace } \\
\hline Yes & $10,695(48.3)$ & $444(100)$ & 0.6475 \\
\hline \multicolumn{4}{|c|}{ Secondhand smoke exposure in public places } \\
\hline Yes & $20,453(92.4)$ & $414(93.2)$ & 0.1936 \\
\hline
\end{tabular}

\section{Asthma occurs due to second-hand smoke status -}

Outside activity is the main influencing factors for second-hand smoke exposure. The results showed a reduction in the occurrence of asthma (Table 3). As a result, it had a big impact even when strenuous exercise was only carried out for at least 1 - 2 days $(\mathrm{p}=0.0233)$. The rest of the results, showed a significant difference at 5 - 7 days (5 days: 68 [15.3\%], 6 days: 26 [5.9\%], 7 days: 214 [48.0\%]) with light walking for more than 10 minutes $(\mathrm{p}=0.003)$ (Table 3 ).

Table 3. Relationship between external factors and asthma

\begin{tabular}{|c|c|c|c|}
\hline & $\mathrm{N}=24,794(\%)$ & $\begin{array}{l}\text { Doctor diagnosed, } \\
\mathrm{N}=444(\%)\end{array}$ & ${ }^{\text {asthma }} \boldsymbol{p}$-value* \\
\hline Physical exertion over a week & $1,859(8.4)$ & $47(10.6)$ & \multirow{8}{*}{0.0233} \\
\hline 2 days & $1,418(6.4)$ & $41(9.2)$ & \\
\hline 3 days & $1,390(6.3)$ & $29(6.5)$ & \\
\hline 4 days & $503(2.3)$ & $13(2.9)$ & \\
\hline 5 days & $790(3.6)$ & $26(5.9)$ & \\
\hline 6 days & $298(1.4)$ & $10(2.3)$ & \\
\hline 7 days & $567(2.6)$ & $15(3.4)$ & \\
\hline Walking days ( $>10$ minutes) & & & \\
\hline 1 day & $963(4.4)$ & $27(6.1)$ & \multirow{7}{*}{0.003} \\
\hline 2 days & $1,474(6.7)$ & $19(4.3)$ & \\
\hline 3 days & $2,108(9.5)$ & $27(6.1)$ & \\
\hline 4 days & $1,217(5.5)$ & $17(3.8)$ & \\
\hline 5 days & $3,416(15.4)$ & $68(15.3)$ & \\
\hline 6 days & $1,270(5.7)$ & $26(5.9)$ & \\
\hline 7 days & $8,390(37.9)$ & $214(48.0)$ & \\
\hline
\end{tabular}

\section{E. Effect of smoking on asthma and multifaceted effects-}

In terms of factors that occurred in conjunction with current smoking, the risk was increased 1.5 with smoking in respondents with ongoing asthma and asthma diagnoses in the past. These results were statistically significant ( $\mathrm{p}=0.0008$, 
0.007). For the items "I have never smoked tobacco" (78.5\%), "daily smokers" $(19.6 \%, \mathrm{p}=0.0010)$, and "occasional smokers" $(2.0 \%, \mathrm{p}=0.0011)$, the respondents seem to affect the historical and current asthma diagnosis smoke does not reach (Table 4).

Table 4. Relationship between smoking and disease (asthma *DX, Current asthma treatment)

\begin{tabular}{|c|c|c|c|c|c|}
\hline \multirow[t]{2}{*}{ Lifetime smoking (+) } & $\mathrm{N}=24,794(\%)$ & $\begin{array}{l}\text { Doctor diagnosed, } \\
\text { sthma **aOR }(+)\end{array}$ & $p$-value $* * *$ & $\begin{array}{l}\text { Current asthma } \\
\text { Treatment, } * *_{\mathrm{a}} \mathrm{OOR}(+)\end{array}$ & $p$-value $* * *$ \\
\hline & $5,982(27.0)$ & $1.504(1.18-1.91)$ & 0.0008 & $1.505(1.18-1.91)$ & 0.0007 \\
\hline \multicolumn{6}{|l|}{ Age whensmoking started (2) } \\
\hline$<15$ years old & $805(3.6)$ & $0.052(<0.01->99.9)$ & \multirow{4}{*}{0.9148} & $0.051(<0.01->99.9)$ & \multirow{4}{*}{-0.9282} \\
\hline $16-20$ years old & $4,353(19.7)$ & $0.063(<0.01->99.9)$ & & $0.060(<0.01->99.9)$ & \\
\hline $21-25$ years old & $793(3.6)$ & $0.025(<0.01->99.9)$ & & $0.022(<0.01->99.9)$ & \\
\hline$>26$ years old & $25(0.1)$ & $1.245(<0.01->99.9)$ & & $1.243(<0.01->99.9)$ & \\
\hline \multicolumn{3}{|l|}{ Current smoking (3) } & \multirow{4}{*}{0.0010} & & \\
\hline Everyday & $4,327(19.6)$ & $0.676(0.39-1.18)$ & & $0.680(0.39-1.18)$ & \multirow{3}{*}{0.0011} \\
\hline Sometimes & $435(2.0)$ & $0.714(0.49-1.05)$ & & $0.713(0.49-1.05)$ & \\
\hline Do not smoke. & $17373(78.5)$ & $1.329(1.01-1.75)$ & & $1.330(1.01-1.75)$ & \\
\hline \multicolumn{6}{|l|}{ Past smoking period (7) } \\
\hline$<1$ year & $303(1.4)$ & $0.494(0.15-1.64)$ & \multirow{3}{*}{0.3037} & $1.617(0.36-7.26)$ & \multirow{3}{*}{0.3002} \\
\hline $2-5$ years & $593(2.7)$ & $0.973(0.24-3.96)$ & & $0.98(0.24-4.00)$ & \\
\hline$>5$ years & $319(1.5)$ & $0.602(0.13-2.80)$ & & $0.59(0.06-5.50)$ & \\
\hline
\end{tabular}

* Asthma DX: asthma diagnosis

*** Adjusted for Age, gender, height, weight, income, and basic living security received

*** Individual characteristic; EA, economic activity; aOR, adjusted odds ratio; CI, confidence interval; NA, no answer

\section{$F$. The aggravating factors of asthma and multifaceted effects-}

In terms of factors exacerbating asthma exacerbations, mental health can be seen as a major factor depending on a variety of factors of smoking (Figure 2). The results from this study for "The plan is not for a year of smoking" and "I will never quit smoking", showed a risk of 1.04 , and 1.91 increase, which was statistically significant $(\mathrm{p}=0.0068)$. If the respondents did not stop smoking for a year, the risk of asthma increased to 1.39. In terms of mental health, depression caused an increase of 2.57. For participants who responded that "I have thought about suicide," it increased to 2.79, and for those who stated, "I have attempted suicide," it increased to 4.34 (Figure 1).

Figure 1. The relationship between asthma exacerbation and mental health

(a) and (b) : Asthma exacerbation Question: Did the symptoms of asthma exacerbation during the last year? and (c) Asthma exacerbation Question: Did the symptoms of asthma exacerbation during the last year?

(a)

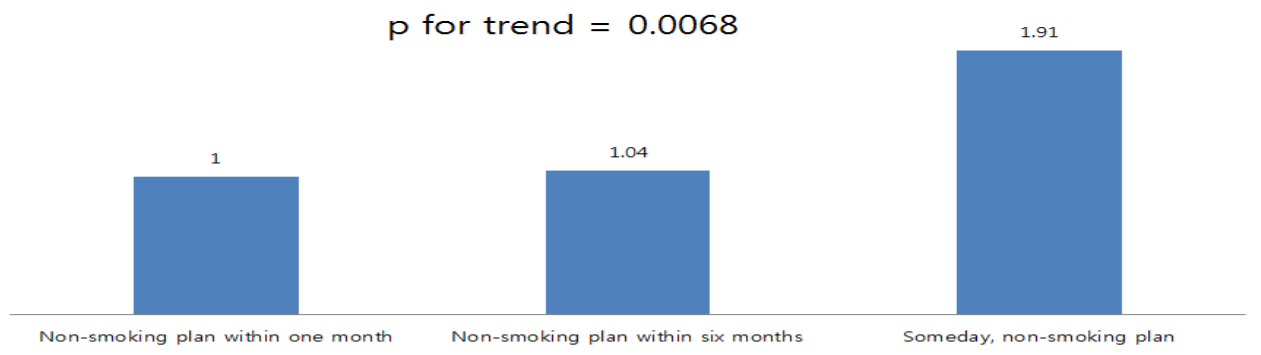

(b)

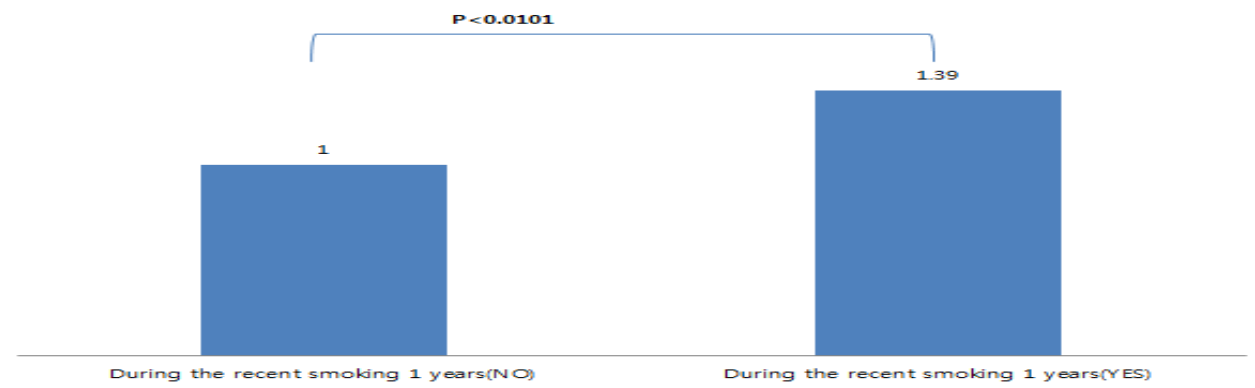

* Adjusted for age, gender, height, weight, income, and basic living security received people 
(c)

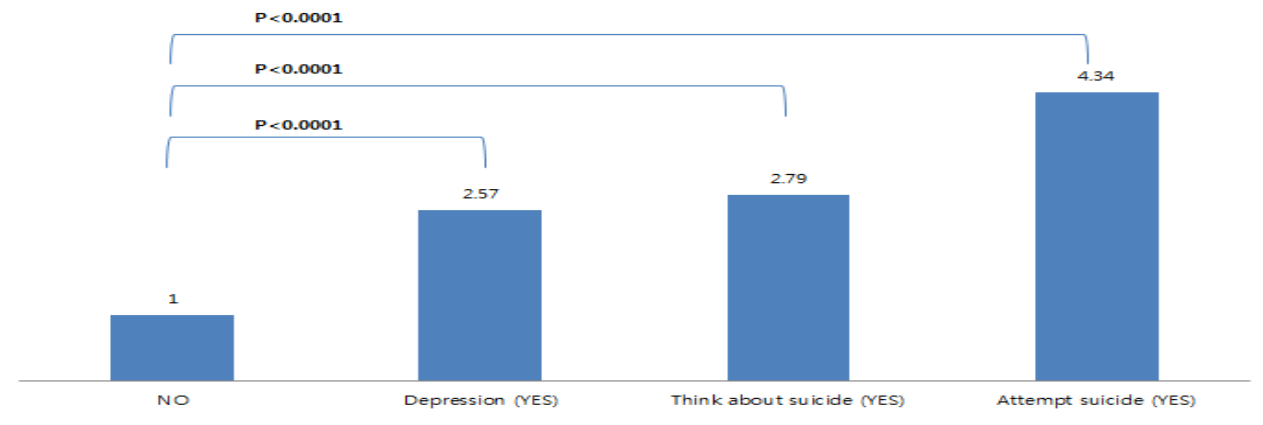

* Adjusted for age, gender, height, weight, income, and basic living security received people

\section{DISCUSSION}

This study clarified the effects of smoking and second-hand smoke exposure in youth on the occurrence of asthma. There appeared to be an increased prevalence of asthma according to smoking and second-hand smoke exposure [8, 9]. Among the factors was the major variable of exposure to smoking in childhood, which relates to direct and indirect smoking. Such research could focus on continuous exposure to smoking in youth and childhood. In this study, exposure to smoking was high in patients 21 - 23 years of age $(12.6 \%, 11 \%, 14 \%)$ at diagnosis of asthma. Furthermore, at 26 - 29 years of age $(11 \%, 9.7 \%$, $7.2 \%, 9 \%)$, there appeared to be a slight increase $(\mathrm{p}=0.0372)$.

Youth defined as having asthma have been found to be two to four times more likely to start smoking than non-susceptible youth $[17,18,19]$. Consequently, smoking has a negative impact on the economy and affects policy effectiveness in many areas. The present study showed that asthma is a major factor in smoking, and this understanding can help to formulate a variety of initiatives to reduce smoking and exposure to second-hand smoke. Addressing smoking in these environments can prevent a wide range of exposure [20].

There were statistically correlations between asthma and long-term exposure to second-hand smoke $(0.2 \%)$ and exposure in the home for 3 years $(2.5 \%)$. The association between lifetime smoking and current smoking with current asthma treatment and a doctor's diagnosis asthma was stronger among youth aged 21, 23, 29, and 30 years (over 9\%) compared with young adults ages 24 to 27 years (less than 9\%). The interactions between a doctor's diagnosis of asthma and second-hand smoke exposure in the home by period $(\mathrm{p}=0.022)$.

Interactions were found for lifetime smoking (diagnosed asthma: aOR, 1.50 [95\% CI: 1.18-1.91]), current asthma treatment (diagnosed asthma: aOR, 1.51 [95\% CI: 1.18-1.91]), current smoking for non-smokers (diagnosed asthma: aOR, 1.33 [95\% CI: 1.01-1.75]), and current asthma treatment (diagnosed asthma: aOR, 1.33 [95\% CI: 1.01-1.75]). Limitation, these selfreported data can introduce bias into the analyses. The questionnaire, which limit to determine the factors that can lead to a variety of factors and disease in 20 healthy, it was reported that the main acts on the direct and indirect impacts such as psychological than physical activity status. So, it was considered that exposure to smoking had a greater effect on the diagnosis and treatment of asthma than variables related to school and work. This may reduce the quality of life due to the twenties [16, 21-23]. The plan to quit smoking increased the risk in association with the timeframe given. The risks for "one month," "six months," or "someday" were 1.04 and 1.91. In terms of smoking, the risk increased to 1.39 in response smoking in the past year versus not smoking during this time. In addition to the direct effect of asthma, mental health, depression, and suicide attempts have been reported to affect asthma. In this study, the results showed the diversity in the twenties, healthy, and what to do to prevent greater exposure. Among them, it can be considered a major factor in youth smoking exposure.

\section{CONCLUSIONS}

This study showed that government efforts are needed to address the major factors of consideration. In addition, individuals' exposure to tobacco should be considered. Toxicity of asthma exists in Korea and other industrialized nations. Our results suggest that the public health result of smoking and second-hand smoke significantly increase asthma morbidity. As a result, smoking affects health and represents a risk factor for asthma. A limitation is that this study did measure smoking and second-hand smoke dependency, which could be significant determinant of persistent smoking among asthmatics who failed to quit despite of ongoing respiratory symptoms. In conclusion, it is thought that the government should change the perception of smoking and exposure to children and adolescents. Small amounts of smoking and secondhand smoke are affecting pulmonary function in adolescence.

Funding: This research was supported by a fund (090-091-4800-4849-306) from the Health Promotion Fund of Korea. Running title: health-related behaviors among adults in Korea 


\section{REFERENCES}

[1] Kan K, Kim YH, "A research on an actual state of drinking and smoking of elementary school children", Korean Journal of Child Health Nursing, 2000, Vol. 6, No. 1, pp. 51-9.

[2] Backinger C, Fagan P, Matthews E, Grana R., "Adolescent and young adult tobacco prevention and cessation: current status and future directions", Tobacco control, 2003, Vol. 12, No. suppl 4, pp. iv46-iv53.

[3] Al Mamun A, O'callaghan FV, Alati R, O'callaghan M, Najman JM, Williams GM, et al., "Does maternal smoking during pregnancy predict the smoking patterns of young adult offspring? A birth cohort study", Tobacco control, 2006, Vol. 15, No. 6, pp. 452-7.

[4] Alexopoulos EC, Jelastopulu E, Aronis K, Dougenis D., "Cigarette smoking among university students in Greece: a comparison between medical and other students", Environmental health and preventive medicine, 2010, Vol. 15, No. 2, pp. 115-20.

[5] Mokdad AH, Marks JS, Stroup DF, Gerberding JL., “Actual causes of death in the United States, 2000”, Jama, 2004, Vol. 291, No. 10, pp. 1238-45.

[6] Choi EJ, Kang, E. J., Kim, N. Y., Kim, K. N., Park, M. H., \& Lee, N. H., "The Third Korea National Health and Nutrition Exami nation Survey (KNHANES III) 2005 (health behavior of adults)", Ministry of Health and Welfare \& Korea Institute for Health and Social Affairs, 2006, pp. 54-61.

[7] Choi JS, Lee, J. S., Yoo, G. Y., Shin, H. R., Lee, W. C., Lee, K. J., et al., "Analysis of Korean major diseases and heal th behavior", Ministry of Health and Welfare \& Korea Institute for Health and Social Affairs, 2003, pp. 313-28.

[8] Carter ER, Debley JS, Redding GR., "Chronic productive cough in school children: prevalence and associations with asthma and environmental tobacco smoke exposure", Cough, 2006, Vol. 2, No. 1, pp. 11.

[9] Frank P, Morris J, Hazell M, Linehan M, Frank T., "Smoking, respiratory symptoms and likely asthma in young people: evidence from postal questionnaire surveys in the Wythenshawe Community Asthma Project (WYCAP)", BMC pulmonary medicine, 2006, Vol. 6, No. 1, pp. 10.

[10] Health UDo, Services H., "The health consequences of using smokeless tobacco: a report of the advisory committee to the Surgeon General. US Department of Health and Human Services, Public Health Service, National Institutes of Health, National Cancer Institute", DHHS Publication No.(NIH), 1986.

[11] Organization WH, Initiative TF., "Protection from exposure to second-hand tobacco smoke: policy recommendations", World Health Organization, 2007.

[12] Organization WH., "WHO report on the global tobacco epidemic, 2009: implementing smoke-free environments", 2009.

[13] Brim SN, Rudd RA, Funk RH, Callahan DB., "Asthma prevalence among US children in underrepresented minority populations: American Indian/Alaska Native, Chinese, Filipino, and Asian Indian”, Pediatrics, 2008, Vol. 122, No. 1, pp. e217-e22.

[14] Strachan DP, Cook DG., "Parental smoking and childhood asthma: longitudinal and case-control studies", Thorax, 1998, Vol. 53. No. 3, pp. 204-12.

[15] Control CfD, Prevention, Control CfD, Prevention., "National health and nutrition examination survey", 2010.

[16] Moonie SA, Sterling DA, Figgs L, Castro M. "Asthma status and severity affects missed school days", Journal of School Health, 2006, Vol. 76, No. 1, pp. 18-24.

[17] Vork K, Broadwin R, Blaisdell R., "Developing asthma in childhood from exposure to secondhand tobacco smoke: insights from a metaregression", Ciência \& Saúde Coletiva, 2008, Vol. 13, No. 4, pp. 1313-25.

[18] Gerald LB, Gerald JK, Gibson L, Patel K, Zhang S, McClure LA., "Changes in environmental tobacco smoke exposure and asthma morbidity among urban school children”, CHEST Journal, 2009, Vol. 135, No. 4, pp. 911-6.

[19] Suh M, Kim H-H, Sohn MH, Kim K-E, Kim C, Shin DC., "Prevalence of allergic diseases among Korean school-age children: a nationwide crosssectional questionnaire study", Journal of Korean medical science, 2011, Vol. 26, No. 3, pp. 332-8.

[20] Rachiotis G, Siziya S, Muula AS, Rudatsikira E, Papastergiou P, Hadjichristodoulou C., "Determinants of exposure to Environmental Tobacco Smoke (ETS) among non smoking adolescents (aged 11-17 years old) in Greece: results from the 2004-2005 GYTS Study", International journal of environmental research and public health, 2010, Vol. 7, No. 1, pp. 284-90.

[21] Ryu YJ, Chun E-M, Lee JH, Chang JH., "Prevalence of depression and anxiety in outpatients with chronic airway lung disease", The Korean journal of internal medicine, 2010, Vol. 25, No. 1, pp. 51.

[22] Meng Y-Y, Babey SH, Wolstein J., "Asthma-related school absenteeism and school concentration of low-income students in California”, Preventing chronic disease, 2012, pp. 9.

[23] Hong SJ, Lee MS, Sohn M, Shim J, Han Y, Park K, et al., "Self- reported prevalence and risk factors of asthma among Korean adolescents: 5- year follow- up study, 1995-2000", Clinical \& Experimental Allergy, 2004, Vol. 34, No. 10, pp. 1556-62. 